\title{
Closing the Gap between Interdisciplinary Research and Disciplinary Teaching
}

\author{
Brian P. Coppola*, Mark M. Banaszak Holl, and Katrin Karbstein \\ Department of Chemistry, University of Michigan, Ann Arbor, Michigan 48109-1055
}

A s Ph.D. students, and then as postdoctoral associates, future academicians spend $6-8$ years getting ready to push hard on the boundaries and interfaces where traditional areas of science overlap. More than ever, however, this broadens the separation between what that faculty member is prepared to carry out in the laboratory and what is expected from a professor in the undergraduate teaching program, where there are-and always will be-significant needs for faculty members who are equally comfortable with the subject matter at the dead-center core of the traditional disciplines. Because the leading edges of research are interdisciplinary and increasing numbers of Ph.D.s are granted in these areas, this disconnect between a future faculty member's scientific education and the needs for undergraduate and graduate teaching will continue to grow.

One response to this disconnect might be, "Well, we should be teaching in the new interdisciplinary areas and not in the traditional ones." This is not a defensible position. First, understanding in the interdisciplinary areas generally relies on fundamentals drawn from the traditional areas. Second, at least in the U.S., the need for instruction in the traditional areas, mainly in the large, introductory service courses, is not going away, nor is the need for that content. These are service courses primarily, with only a small fraction of students who would be joining us in the discipline, so the needs of the majority must be paramount. Third, these courses truly pay the bills for depart- ments, so simply neglecting them is not a credible option.

At the University of Michigan, we are attending to this gap between interdisciplinary research and the need for future faculty to teach in core disciplinary areas by offering dual-mentorship postdoctoral opportunities as a part of a program to improve the preparation of students for academic careers.

Our approach differs from the usual "teaching postdoc" in significant ways: faculty-centered research is still the main driver, and the teaching component is explicitly structured as a training activity. In the chemistry department, faculty members recruit and interview potential postdoctoral associates in exactly the same way and with the same criteria as they always have. However, the faculty members also know that they can add a teaching component to their recruiting efforts when they sense that this might be important to the potential new postdoctoral associate. Indeed, we have never advertised this program precisely because we do not want the teaching component to drive a student's interest.

From a practical perspective, the program works this way: a postdoctoral associate who is a regular member of one of our research groups can also have a regular teaching assignment in the department as well as a faculty member who is their teaching mentor. The expectation is that, in the term in which the postdoc has a teaching assignment, his or her workload is $50 \%$ teaching and $50 \%$ research. During that se-

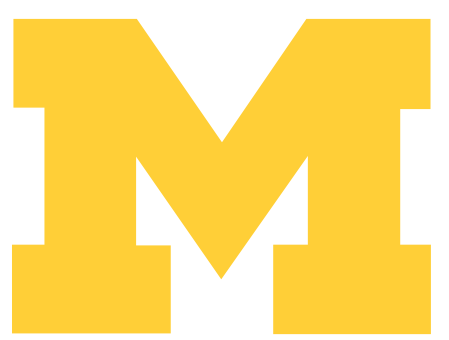

*Corresponding author, bcoppola@umich.edu.

Published online August 17, 2007 10.1021/cb7001544 CCC: $\$ 37.00$ ๑) 2007 American Chemical Society 
mester, the department contributes a standard, fixed-rate contribution to the stipend and benefits for this person and makes available a small amount of discretionary money for travel. In practice, the postdocs in this program teach for one or two semesters out of a two-year time period.

Our postdoctoral associates have had teaching assignments that cover the range of courses in our undergraduate program. They are matched with courses by a combination of their interests, the department's needs, and the availability of a teaching mentor for the course. A common teaching assignment would be as one of the 3-6 instructors in one of our large introductory general or organic chemistry courses. These multisection courses are treated as one large course, and one of the experienced instructors serves as the course coordinator. In this way, a postdoctoral instructor in this course is essentially the same as any of our new faculty members who are cycling into this course for the first time. Our existing course infrastructure provides a great deal of the built-in mentoring that is expected and available. The dual-mentorship postdoctoral associate is co-listed with his or her faculty mentor as the instructors for the course, or a specific section of the course, although the postdoc handles the instructional load. Every aspect of designing and implementing a course that a new faculty member might be expected to do, from creating the syllabus to writing and scoring exams to assigning grades, is done in consultation and collaboration with an experienced faculty member.

As a department, we see the members of our future faculty community, which includes these postdocs as well as graduate and undergraduate students interested in academic careers, as colleagues and collaborators with us in our teaching program as much as they are in our research program (1-4). Consequently, we have an expectation that these individuals will help us as we develop new courses, new teaching materi- als, and new teaching methods. They are members of "teaching groups" in the same way they are members of research groups. Broadening this sense of professional collaboration, which is the cornerstone for how research is done, is the foundational concept for how we think about preparing future faculty for their teaching obligations. As a part of our continued commitment to these principles, the department has recently created a highly competitive postdoctoral fellowship program to which individuals may apply (see Box 1).

In addition to these teaching experiences, we offer a seminar program of external speakers who address topics of interest to future faculty members, usually around the areas of teaching and learning. We also tap into the local strengths and experiences of our faculty and administrators with a regular series of brown-bag panel discussions on a breadth of relevant issues, such as interviewing for an academic job, understanding the promotion and tenure process, running research groups, writing proposals, and interacting with journal editors and the publication process. We also invite faculty members from different types of institutions to participate as panelists so that the perspective on these issues is broader than ours.

Most importantly, all of our participants are still first and foremost the best scientists we have and not a separate or segregated subset of faculty members and students who are the "educationalists". Rather, they are that subset of mainstream scientists in the department who simply want to add this work to their portfolio. For postdoctoral associates who have spent their formative years at the edge of their interdisciplinary research area, the teaching assignment in a core disciplinary area provides a unique and important experience in their education that will, in general, provide them with a competitive advantage on the job market.

The experiences of University of Michigan chemistry professor Mark Banaszak Holl are indicative of someone who has taken 175 advantage of these resources. Mark had a 176 vision of studio-based instruction, where 177 there was no separation between lecture 178 and laboratory, just a series of learning $\quad 179$ goals that would be addressed by the most 180 effective teaching method that might be 181 aligned with that goal. Mark has premier re- 182 search programs in inorganic chemistry and 183 nano-medicine, and his work spreads from 184 physics to biology. Naturally, the only way 185 he can involve himself in this degree of re- 186 search activity is as a part of an interdiscipli- 187 nary research team. The scope of this "stu- 188 dio chemistry" idea represented exactly the 189 same challenge. To date, he has worked 190 with a steady-state team of a postdoctoral 191 associate, 3-4 graduate students, and 1-3 192 undergraduates, as well as two faculty col- 193 laborators, on the development, implemen- 194 tation, and assessment of his vision of 195 studio chemistry. Just as in any successful 196 research group, Mark's postdoctoral associ- 197 ate, Amy Gottfried, quickly took on the intel- 198 lectual leadership of the studio project and 199 has been much more involved than Mark in 200 its day-to-day details (5).

Between September 2002 and mid2007, we have had 19 of these postdocs; 11 of them are still in residence. Of the eight 204 who have completed their postdoc, five of 205 them are currently in tenure-track positions 206 at a variety of institutions, two of them begin 207 their new positions in the fall, and one is, 208 as of this writing, negotiating her offer. 209

The response to this program from our 210 postdoctoral associates has been uniformly 211 positive and enthusiastic. One of our new 212 postdoctoral associates, reflecting on her 213 choice to accept the offer from our depart- 214 ment (instead of one of her other offers) said 215 that the dual-mentorship program made a 216 difference: "I chose to pursue [this] postdoc 217 because of the combined teaching and re- 218 search opportunities. I wanted to gain expe- 219 rience teaching a college course while con- 220 ducting research prior to obtaining an 221 academic position. The skills I am going to 222 
learn (multitasking, curriculum development, public speaking, etc.) will benefit me greatly in a faculty position, since I believe it will give me a head start in the transition to an academic position."

Another individual, who is in the middle of his postdoctoral period, has had a semester of teaching: "The main benefit of the teaching postdoc program has allowed me to get a glimpse of what it would be like to be a faculty member. Some of the perks include learning how to balance research and teaching, which is not always easy, but definitely worth the effort."

Two students who had particularly extraordinary interdisciplinary educations, with individual research projects that included work from casting polymers to doing in vivo bioanalytical measurements, have shared their positive experiences. The first said, "The biggest benefit has been to develop communication skills outside my specific disciple of study. I think that I have developed the ability to both listen to other people (and understand that their perspective and approach to intellectual projects and problems are different than mine) and to explain myself-and my perspective-to people in other disciplines. I think this was integral to my interview process in biomedical engineering." A second student from this same research group, who ended up applying for a position as an organic chemistry faculty member, noted that having learned about the structure of universities (and how things work) made a big difference in how she was viewed during the interview: "I knew these things already, so after the first couple of conversations, they stopped talking down to me." Because it is impossible to fake sincerity, it was clear during her interview that she had had a truly first-hand experience as the instructor of a course, and her interviewers once again related to her more as an experienced colleague than as an inexperienced recruit. Insight into the politics of departments helped also: "I could recognize who were the ones who held the

\section{Box 1. Michigan Fellows in Chemistry}

Recognizing that world-class scientific achievements are required but not sufficient for obtaining faculty positions at top institutions and becoming a successful faculty member, the chemistry department at the University of Michigan has taken a number of steps designed to strengthen training of graduate students and postdoctoral associates, as well as mentoring of young faculty members. As a result, the department has been able to successfully recruit and retain many top young scientists, including women and minority faculty. To further strengthen the postdoctoral training program, the department has recently created a new postdoctoral fellowship program. This program provides both a competitive salary $(\$ 50,000 /$ year and benefits), as well as an outstanding future faculty preparation program, to recruit top recent graduates to Michigan for postdoctoral research. The faculty preparation program is built on the opportunities provided and tested by the dual-mentorship postdoctoral program described in this article and as such includes faculty preparation seminars and the opportunity to teach small workshops on an area of interest and expertise, among other opportunities. In addition, the new Michigan Fellows in Chemistry program provides the fellows with shared office space. An office gives fellows a quiet space to write papers and develop their research plans and fosters interactions among fellows from different disciplines. Monthly lunches, introduced successfully to support the early careers of assistant professors in the chemistry department, are also encouraged, with the goal of creating a peer group of postdoctoral fellows. Further, the program provides the opportunity to host and meet seminar speakers in their office, and this helps connect future faculty applicants. Thus, this program is designed to help the fellows obtain excellent faculty positions on the basis of their outstanding scientific accomplishments. For further information on the program, visit www.umich.edu/ michchem/fellows/index.html.

cards in the department and could answer accordingly."

In the end, the department thinks that getting this kind of experience can only benefit the future of these students from a quite simple and practical perspective. In whatever setting they end up in for their own independent faculty careers, they will not have to waste time, their most valued commodity, dealing with their first-ever teaching assignments from a position of complete ignorance. According to the reports of those who have gone on, the dual-mentorship experience provides them with one of the winning characteristics of any successful faculty member: efficiency. They are able to more successfully manage their teaching obligations, earlier on, and with less effort, freeing time for research or other tasks de- manding their attention during those tumultuous first years as a faculty member. We think this is a more responsible way to serve the educational needs of not only our postdoctoral associates but, by proxy, all of the students who are in their classes.

\section{REFERENCES}

1. Coppola, B. P., and Roush, W. R. (2004) Broadening the existing intergenerational structure of scholarly development in chemistry, Peer Rev. 6, 19-21.

2. Coppola, B. P. (2007) The most beautiful theories... J. Chem. Educ., in press.

3. Coppola, B. P. (2007) Faculty roles and rewards, in Creating a Culture/Climate That Supports Undergraduate Teaching and Learning in STEM, New Directions in Teaching and Learning series (Baldwin, R., Ed.) Jossey-Bass, San Francisco, in press.

4. Caserio, M., Coppola, B. P., Lichter, R. L., Bentley, A. K., Bowman, M. D., Mangham, A. N., Metz, K. M., Pazicni, S., Phillips, M. F., and Seeman, J. I. (2004) Responses to changing needs in U.S. doctoral education, J. Chem. Ed. 81, 1698-1705. 
5. Gottfried, A. C., Sweeder, R. D., Bartolin, J. M., Hessler, J. A., Reynolds, B. P., Stewart, I. C., Coppola, B. P., and Banaszak Holl, M. M. (2007) Design and implementation of a studio-based general chemistry course at the University of Michigan, J. Chem. Ed. 84, 265270. 